\title{
Effect of RF Power on the Properties of Sputtered-CuS Thin Films for Photovoltaic Applications
}

\author{
Donghyeok Shin ${ }^{1}$, SangWoon Lee ${ }^{1}$, Dong Ryeol Kim ${ }^{2,3}$, Joo Hyung Park ${ }^{2}$, Yangdo Kim ${ }^{1}$, \\ Woo-Jin Choi ${ }^{4}$ (D) Chang Sik Son ${ }^{5}$, Young Guk Son ${ }^{1, *}$ and Donghyun Hwang ${ }^{5, *(D)}$ \\ 1 School of Materials Science and Engineering, Pusan National University, Busan 46241, Korea; \\ 201883628@pusan.ac.kr (D.S.); 201983325@pusan.ac.kr (S.L.); yangdo@pusan.ac.kr (Y.K.) \\ 2 Photovoltaics Laboratory, Korea Institute of Energy Research, Daejeon 34129, Korea; \\ drkim@kier.re.kr (D.R.K.); joopark@kier.re.kr (J.H.P.) \\ 3 School of Materials Science and Engineering, Kyungpook National University, Daegu 41566, Korea \\ 4 Energy Convergence Technology Center, Silla University, Busan 46958, Korea; cwjgod@naver.com \\ 5 Division of Materials Science and Engineering, Silla University, Busan 46958, Korea; csson@silla.ac.kr \\ * Correspondence: ykson@pusan.ac.kr (Y.G.S.); dhhwang@silla.ac.kr (D.H.); Tel.: +82-10-4553-0034 (Y.G.S.); \\ +82-10-3156-4055 (D.H.)
}

Received: 6 January 2020; Accepted: 3 February 2020; Published: 5 February 2020

\begin{abstract}
Copper sulfide (CuS) thin films were deposited on a glass substrate at room temperature using the radio-frequency (RF) magnetron-sputtering method at RF powers in the range of 40-100 W, and the structural and optical properties of the CuS thin film were investigated. The CuS thin films fabricated at varying deposition powers all exhibited hexagonal crystalline structures and preferred growth orientation of the (110) plane. Raman spectra revealed a primary sharp and intense peak at the $474 \mathrm{~cm}^{-1}$ frequency, and a relatively wide peak was found at $265 \mathrm{~cm}^{-1}$ frequency. In the CuS thin film deposited at an RF power of $40 \mathrm{~W}$, relatively small dense particles with small void spacing formed a smooth thin-film surface. As the power increased, it was observed that grain size and grain-boundary spacing increased in order. The binding energy peaks of $\mathrm{Cu} 2 \mathrm{p}_{3 / 2}$ and $\mathrm{Cu} 2 \mathrm{p}_{1 / 2}$ were observed at 932.1 and $952.0 \mathrm{eV}$, respectively. Regardless of deposition power, the difference in the $\mathrm{Cu}^{2+}$ state binding energies for all the $\mathrm{CuS}$ thin films was equivalent at $19.9 \mathrm{eV}$. We observed the binding energy peaks of $S 2 p_{3 / 2}$ and $S 2 p_{1 / 2}$ corresponding to the $S^{2-}$ state at 162.2 and $163.2 \mathrm{eV}$, respectively. The transmittance and band-gap energy in the visible spectral range showed decreasing trends as deposition power increased. For the CuS/tin sulfide (SnS) absorber-layer-based solar cell (glass/Mo/absorber(CuS/SnS)/cadmium sulfide (CdS)/intrinsic zinc oxide (i-ZnO)/indium tin oxide (ITO)/aluminum (Al)) with a stacked structure of SnS thin films on top of the CuS layer deposited at $100 \mathrm{~W}$ RF power, an open-circuit voltage $\left(\mathrm{V}_{\text {oc }}\right)$ of $115 \mathrm{~mA}$, short circuit current density $\left(\mathrm{J}_{\mathrm{sc}}\right.$ ) of $9.81 \mathrm{~mA} / \mathrm{cm}^{2}$, fill factor $(\mathrm{FF})$ of $35 \%$, and highest power conversion efficiency (PCE) of $0.39 \%$ were recorded.
\end{abstract}

Keywords: covellite; CuS thin film; CuS/SnS absorber; RF magnetron sputtering; solar cell

\section{Introduction}

Copper sulfide (CuS) is a transition metal chalcogenide in the IB-VIA group. The material is a typical p-type semiconductor where holes are the major carrier, $\mathrm{Cu} 4 \mathrm{~s}$ and $\mathrm{S} 3 \mathrm{p}$ hybridized states become the conduction-band minimum, and the $\mathrm{Cu} 3 \mathrm{~d}$ and $\mathrm{S} 3 \mathrm{p}$ antibonding states become the valence-band maximum [1,2]. Most copper sulfide phases that show semiconductor behavior are reported to exist in four types, $\mathrm{Cu}_{2-\mathrm{x}} \mathrm{S}$ (digenite), $\mathrm{Cu}_{1.96} \mathrm{~S}$ (djurleite), $\mathrm{Cu}_{1.75} \mathrm{~S}$ (anilite), and $\mathrm{CuS}$ (covellite), which are crystallographically and stoichiometrically stable at room temperature $[1,3]$. 
From these, covellite CuS has a peculiar crystallographic structure that allows the reaction and intercalation of alkali metal ions between the S-Cu-S layers [4]. CuS also exhibits outstanding metallic conductivity, as well as physical and chemical properties, which make the material suitable for various electronics applications, such as cathode materials for lithium rechargeable batteries [5], gas sensors [6], photocatalysis [7], and solar cells [2].

CuS thin films are generally grown by methods like spray pyrolysis [8], the hydrothermal method [9], chemical-vapor deposition [10], atomic-layer deposition [11], and sputtering [12]. Among these, radio-frequency (RF) magnetron sputtering, which is one of the physical vapor-deposition methods, employs simple equipment and can form a strong adhesive force between the as-sputtered thin films and the substrate. It is also low-cost and appropriate for large-scale industrial productions, features that increase its potential value in various industrial applications [13,14]. Additionally, the sputtering method allows for the convenient control of various process parameters, such as substrate temperature, deposition time, deposition power, working pressure, and distance between target and substrate. Using the method, it is also relatively easy to produce thin films with consistent properties and control the elemental composition. However, despite these aspects, only a few studies have been reported on the growth of pure covellite CuS thin films using RF magnetron sputtering, and research on the application of covellite CuS thin films as the absorber layer in photovoltaic devices is scarce.

In this study, the RF magnetron-sputtering technique was used to successfully deposit covellite $\mathrm{CuS}$ thin films on a glass substrate, and the structural and optical properties of the CuS thin films were thoroughly investigated according to the process parameter of deposition-power variation (40-100 W). To evaluate the solar-cell application, CuS thin films with the same thickness were deposited under different power conditions on Mo-doped glass substrates at room temperature. Then, tin sulfide (SnS) thin films were directly stacked on top of the CuS thin film to produce an absorber layer with a CuS/SnS structure. Finally, we evaluated the electrical properties of the CuS/SnS absorber-based solar cell fabricated by stacking the buffer layer, window layer, and electrode on top of the CuS/SnS absorber.

\section{Materials and Methods}

A CuS target (TASCO, Seoul, Korea) of $50 \mathrm{~mm}$ (1.97 inch) diameter, $4 \mathrm{~mm}$ ( 0.16 inch) thickness, and $99.999 \%(5 \mathrm{~N})$ purity was installed on a target fixture located in the upper part of the chamber, so that the distance between target and substrate was $100 \mathrm{~mm}$. Soda-lime glass was cut into $25 \times 25 \mathrm{~mm}$ squares and used for the substrate, and fine particles and other contaminants produced by the cutting process were removed using an $\mathrm{N}_{2}$ gas gun. Residual organic matter on the specimen surface was removed through ultrasonic cleaning for 5 min using deionized (DI) water and $99 \%$ purity acetone, ethyl alcohol, and isopropyl alcohol, in the listed order. A UV ozone cleaner was also used for the removal of solvent remaining on the specimen surface, and the cleaning was finished after $20 \mathrm{~min}$ of exposure. The initial pressure of the vacuum chamber was set to below $5.0 \times 10^{-6}$ Torr $(0.67 \mathrm{mPa})$ using a rotary pump and turbo molecular pump (TMP), and working pressure was maintained at $5.0 \times 10^{-3}$ Torr $(0.67 \mathrm{~Pa})$ using a $20 \mathrm{sccm}$ unit inflow of argon (Ar) gas via a mass-flow controller (MFC). Prior to the deposition of the CuS thin film, presputtering was carried out for $20 \mathrm{~min}$ at room temperature (RT) at $60 \mathrm{~W}$ RF power to remove target surface contaminants. The process parameter, RF power, was modified from 40 to $100 \mathrm{~W}$ to conduct $\mathrm{CuS}$ thin-film deposition for $40 \mathrm{~min}$.

For the solar-cell absorber-layer application, CuS thin films of $500 \mathrm{~nm}$ thickness were deposited at room temperature on a molybdenum-coated soda-lime glass substrate. In order to grow CuS thin films of equal thickness, the main process parameter, the RF power, was adjusted from 40 to $100 \mathrm{~W}$, and deposition time was varied at a working pressure condition of $5.0 \times 10^{-3}$ Torr. Additionally, the RF power, substrate temperature, and working pressure were set to $60 \mathrm{~W}, 300{ }^{\circ} \mathrm{C}$, and $1.5 \times 10^{-2}$ Torr $(2.0 \mathrm{~Pa})$, respectively, to stack $500 \mathrm{~nm}$ thickness $\mathrm{SnS}$ thin films on top of the grown CuS thin film. Through this process, the heterojunction absorber layer of a CuS/SnS structure with equal thicknesses was produced. The fabricated absorber layers (CuS/SnS) were immersed in a bath containing 
a solution synthesized with $0.2 \mathrm{M}$ thiourea $\left(\mathrm{CH}_{4} \mathrm{~N}_{2} \mathrm{~S}\right.$, TCI, Tokyo, Japan), $0.003 \mathrm{M}$ cadmium $(\mathrm{Cd})$ sulphate hydrate (CdSO4, Sigma-Aldrich, St. Louis, MO, USA), and $5.95 \mathrm{M}$ ammonium solution $\left(\mathrm{NH}_{4} \mathrm{OH}\right.$, Junsei, Kyoto, Japan). Then, the chemical-bath-deposition (CBD) method was used to synthesize a cadmium sulfide (CdS) buffer layer while maintaining the solution temperature at $80^{\circ} \mathrm{C}$ for $12 \mathrm{~min}$. Intrinsic zinc oxide (i-ZnO) and indium tin oxide (ITO) thin films, corresponding to the window layers, were stacked at 50 and $200 \mathrm{~nm}$ using RF magnetron-sputtering and DC sputtering methods, respectively. Finally, a 1 um thick aluminum (Al) upper electrode was deposited using the thermal-evaporation method, completing the fabricated structure of the CuS/SnS absorber-based solar cell (glass/Mo/absorber(CuS/SnS)/CdS/i-ZnO/ITO/Al), with an active area of $0.4 \mathrm{~cm}^{2}$.

The structural properties of the $\mathrm{CuS}$ thin films were determined using an $\mathrm{X}$-ray diffractometer (XRD, Rigaku, Tokyo, Japan, Ultima IV) employing $\mathrm{CuK}_{\alpha}(\lambda=1.541 \AA)$ radiation in the $2 \theta$ range from $20^{\circ}$ to $80^{\circ}$. Raman spectra in the range from 200 to $700 \mathrm{~cm}^{-1}$ were collected by dispersive Raman microscopy (WItec, Ulm, Germany, Alpha-300R) with an excitation wavelength of $532 \mathrm{~nm}$. The thickness, surface morphology, and chemical composition of the films were observed by field emission scanning electron microscope (FESEM, TESCAN, Brno, Czechia, MIRA 3) combined with energy dispersive $\mathrm{X}$-ray spectroscopy (EDS). The valance states of the constitutive elements were measured by X-ray photoelectron spectroscopy (XPS, Thermo Scientific, Waltham, MA, USA, K-Alpha+) at a binding energy ranging from 0 to $1000 \mathrm{eV}$. The optical transmittance and band gap were studied using an ultraviolet-visible-near-infrared spectrophotometer (UV-Vis-NIR, Jasco, Hachioji, Japan, $\mathrm{V}-570$ ) in the wavelength range of $400-2000 \mathrm{~nm}$. The performance of the CuS/SnS absorber-based solar cells was investigated using a solar simulator (McScience, Yeongtong-gu, Korea, Xe55) at AM $1.5 \mathrm{G}$ illumination.

\section{Results and Discussion}

\subsection{CuS Thin-Film Structural Properties}

The XRD patterns of the CuS thin films are shown in Figure 1. The positions of the diffraction lines matched the location of standard JCPDS card number 00-001-1281 for the crystalline covellite CuS hexagonal phase. The diffraction peaks corresponding to the (101) and (102) planes were observed at $27.3^{\circ}$ and $29.4^{\circ}$, respectively, on the basis of $2 \theta$, while diffraction peaks corresponding to the (103) and (116) planes were observed at $31.8^{\circ}$ and $59.2^{\circ}$, respectively. For all CuS thin films grown using different power conditions, the preferred growth orientation for the (110) plane was observed, and the intensity of the primary diffraction peak increased as the power was increased from 40 to $100 \mathrm{~W}$. The full width at half maximum (FWHM) of the diffraction peak for the (110) plane was 0.58 for $40 \mathrm{~W}, 0.58$ for $60 \mathrm{~W}$, 0.48 for $80 \mathrm{~W}$, and 0.38 at $100 \mathrm{~W}$, showing a decreasing trend. The grain size calculated by substitution into the Scherrer formula [15] revealed that grain size increased from $15.7 \mathrm{~nm}$ at $40 \mathrm{~W}$ to $23.9 \mathrm{~nm}$ at $100 \mathrm{~W}$.

Atomic vibration mode analysis can distinguish spatial variations and surface species in a sample composition, which is generally possible through Raman measurement [16]. Additional analysis of the structural properties of the CuS thin films was conducted by obtaining Raman spectra, and the results are shown in Figure 2. All of the Raman spectra for the CuS thin films deposited at different RF powers showed two bands, with a primary sharp and intense peak at the frequency of $474 \mathrm{~cm}^{-1}$, and a relatively wide peak at the frequency of $265 \mathrm{~cm}^{-1}$. The shark peak in the high-frequency region is the stretching vibrational mode from the covalent $\mathrm{S}-\mathrm{S}$ bonds of $\mathrm{S}^{2-}$ ions at $4 \mathrm{e}$ sites, and this signifies that the lattice atoms were arranged in a periodic array [6]. The broad Raman peak in the low-frequency region corresponded to the mode of the lattice vibration produced by the $\mathrm{Cu}-\mathrm{S}$ bonds [17]. Theoretical analysis revealed that a total of 36 vibrational modes are possible for the $\mathrm{CuS}$ system, and among them, 14 Raman active modes $\left(\Gamma_{\text {Raman }}=2 \mathrm{~A}_{1 \mathrm{~g}}+4 \mathrm{E}_{2 \mathrm{~g}}+2 \mathrm{E}_{1 \mathrm{~g}}\right)$ can be categorized into $\Gamma_{\mathrm{Cu} 1}=\mathrm{A}_{1 \mathrm{~g}}+\mathrm{E}_{2 \mathrm{~g}}+\mathrm{E}_{1 \mathrm{~g}}$, $\Gamma_{\mathrm{Cu} 2}=\mathrm{E}_{2 \mathrm{~g}}, \Gamma_{\mathrm{S} 1}=\mathrm{A}_{1 \mathrm{~g}}+\mathrm{E}_{2 \mathrm{~g}}+\mathrm{E}_{1 \mathrm{~g}}$, and $\Gamma_{\mathrm{S} 2}=\mathrm{E}_{2 \mathrm{~g}}$ for copper $(\mathrm{Cu})$ and sulfur (S) each [1,18]. The covalent $\mathrm{S}-\mathrm{S}$ bonds only exist in the copper-deficient $\mathrm{Cu}_{2-\mathrm{x}} \mathrm{S}(0.6 \leq \mathrm{x} \leq 1)$ phases, so the strong band observed 
at $474 \mathrm{~cm}^{-1}$ is a typical peak characteristic that indicates the covellite CuS phase [19]. Through such Raman analyses, it was determined that CuS thin films with pure covellite CuS phase were fabricated.

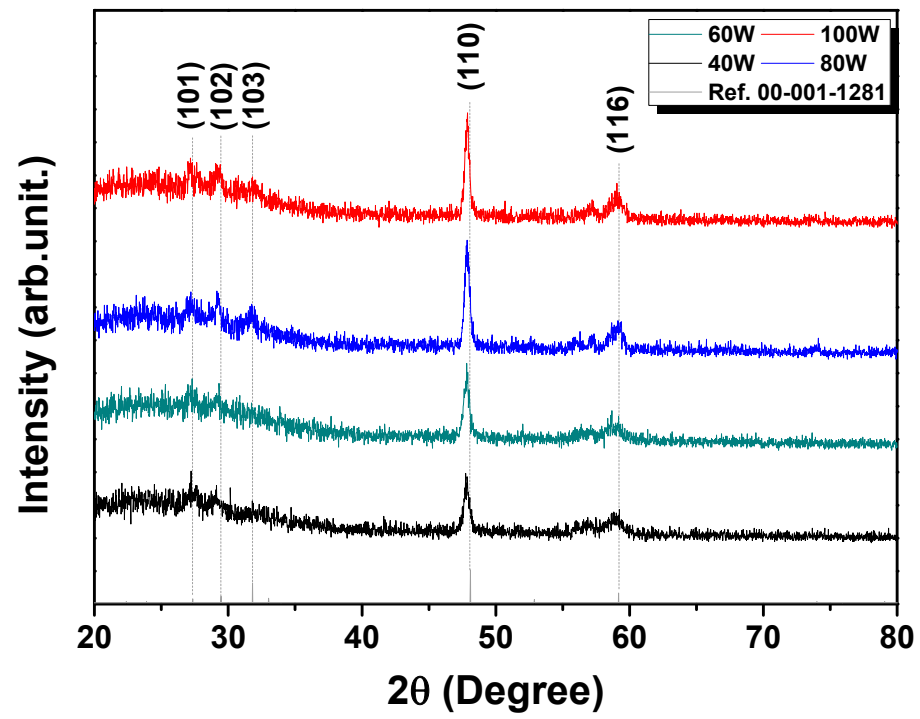

Figure 1. X-ray diffraction (XRD) patterns of copper sulfide (CuS) thin films grown at different sputtering powers.

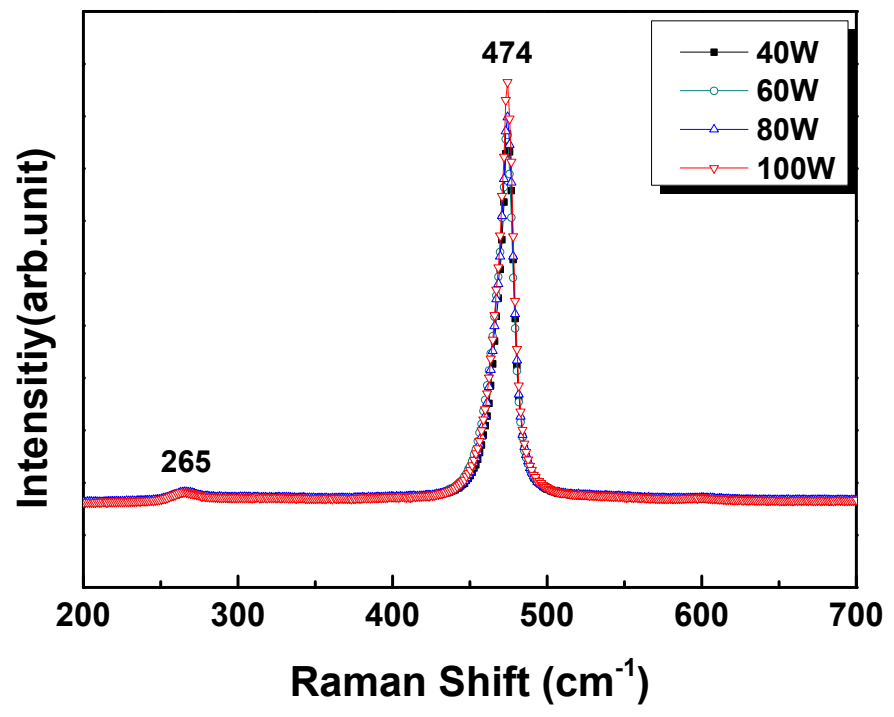

Figure 2. Raman spectra of CuS thin films grown at different sputtering powers.

\subsection{CuS Thin-Film Morphological Properties}

FESEM images of the CuS thin films grown on glass substrates at four different sputtering powers $(40-100 \mathrm{~W})$ are presented in Figure 3. In the case of the CuS thin film deposited with the RF power condition of $40 \mathrm{~W}$, relatively small dense particles with small void spacing composed a smooth and uniform surface, as shown in Figure 3. As the deposition power was increased to $100 \mathrm{~W}$, the grain size gradually increased, and the grain boundaries also increased. This result was in good agreement with XRD analysis results that showed that the FWHM value decreased and crystallite size improved as the deposition power increased. The cross-sectional image of the CuS thin film showed that thickness varied for different deposition powers. Thickness was around $250 \mathrm{~nm}$ for $40 \mathrm{~W}, 310 \mathrm{~nm}$ for $60 \mathrm{~W}$, $460 \mathrm{~nm}$ for $80 \mathrm{~W}$, and $580 \mathrm{~nm}$ for $100 \mathrm{~W}$. It was also observed that CuS thin-film growth occurred in long and flat columnar structures vertically about the glass substrate. 

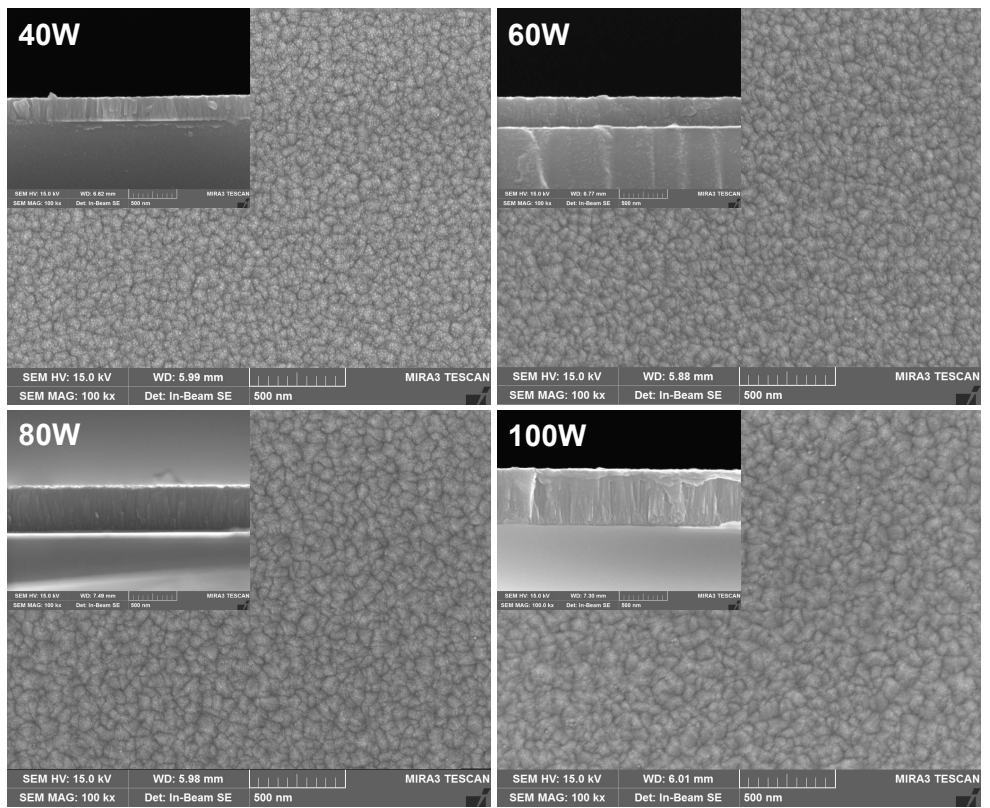

Figure 3. Surface and cross-sectional images of CuS thin films grown at different sputtering powers.

\subsection{CuS Thin-Film Compositional Properties}

The atomic percentages of the CuS thin film according to deposition power, obtained in EDS analyses, are shown in Table 1. The S/Cu ratio of the CuS thin film deposited with the RF power of $40 \mathrm{~W}$ was 0.98 , which was similar to the stoichiometric composition. As deposition power increased, the $\mathrm{S} / \mathrm{Cu}$ ratio was 0.96 for $60 \mathrm{~W}, 0.95$ for $80 \mathrm{~W}$, and 0.94 for $100 \mathrm{~W}$. The $\mathrm{S} / \mathrm{Cu}$ ratio decreased with increasing deposition power compared with a $\mathrm{CuS}$ thin film grown with relatively less $\mathrm{S}$ than $\mathrm{Cu}$. This showed that the $\mathrm{S}$ element was more dependent on deposition power compared to the $\mathrm{Cu}$ element when fabricating CuS thin films using the RF magnetron-sputtering method.

Table 1. Estimated full width at half maximum (FWHM) value, crystalline size, film thickness, and chemical composition of $\mathrm{CuS}$ thin films grown at different sputtering powers.

\begin{tabular}{cccccc}
\hline $\begin{array}{c}\text { Sputtering Power } \\
(\mathbf{W})\end{array}$ & $\begin{array}{c}\text { FWHM Value } \\
\text { (Degree) }\end{array}$ & $\begin{array}{c}\text { Crystallite Size } \\
\mathbf{( n m )}\end{array}$ & $\begin{array}{c}\text { Film Thickness } \\
\mathbf{( n m )}\end{array}$ & \multicolumn{2}{c}{ EDS (Atomic \%) } \\
\hline 40 & 0.58 & 15.7 & 250 & $\mathbf{S}$ & $\mathbf{C u}$ \\
\hline 60 & 0.58 & 15.7 & 310 & 49.6 & 50.6 \\
80 & 0.48 & 18.9 & 460 & 48.9 & 51.1 \\
100 & 0.38 & 23.9 & 580 & 48.4 & 51.6 \\
\hline
\end{tabular}

XPS measurement was carried out to precisely analyze the purity, composition, and valence states of the CuS thin film. Figure 4 shows the XPS results for a specimen with surface impurities removed by etching for $1 \mathrm{~min}$. Strong peaks at 932.1 and $952.0 \mathrm{eV}$ were observed, in good agreement with the literature data regarding the $\mathrm{Cu} 2 \mathrm{p}_{3 / 2}$ and $\mathrm{Cu} 2 \mathrm{p}_{1 / 2}$ binding energies, respectively. This corresponds to the $\mathrm{Cu}^{2+}$ state in the $\mathrm{CuS}$ structure [20]. Theoretically, the difference in binding energies for these two states is $20 \mathrm{eV}$ [9]. For $\mathrm{CuS}$ thin films deposited with varying sputtering powers, the difference in the binding energies of $\mathrm{Cu} 2 \mathrm{p}_{3 / 2}$ and $\mathrm{Cu} 2 \mathrm{p}_{1 / 2}$ was found to be $19.9 \mathrm{eV}$, regardless of the deposition power, which is almost equivalent to the theoretical value. Figure $4 \mathrm{~b}$ shows the result of a high-resolution survey of the $S 2 p$ region, showing that the peaks for the $S 2 p_{3 / 2}$ and $S 2 p_{1 / 2}$ binding energies were 162.2 and $163.2 \mathrm{eV}$, respectively [21]. The XPS analysis result indicated that $\mathrm{Cu}$ and $\mathrm{S}$ oxidation states clearly exist on $\mathrm{CuS}$ thin films deposited at varying degrees of RF power. 

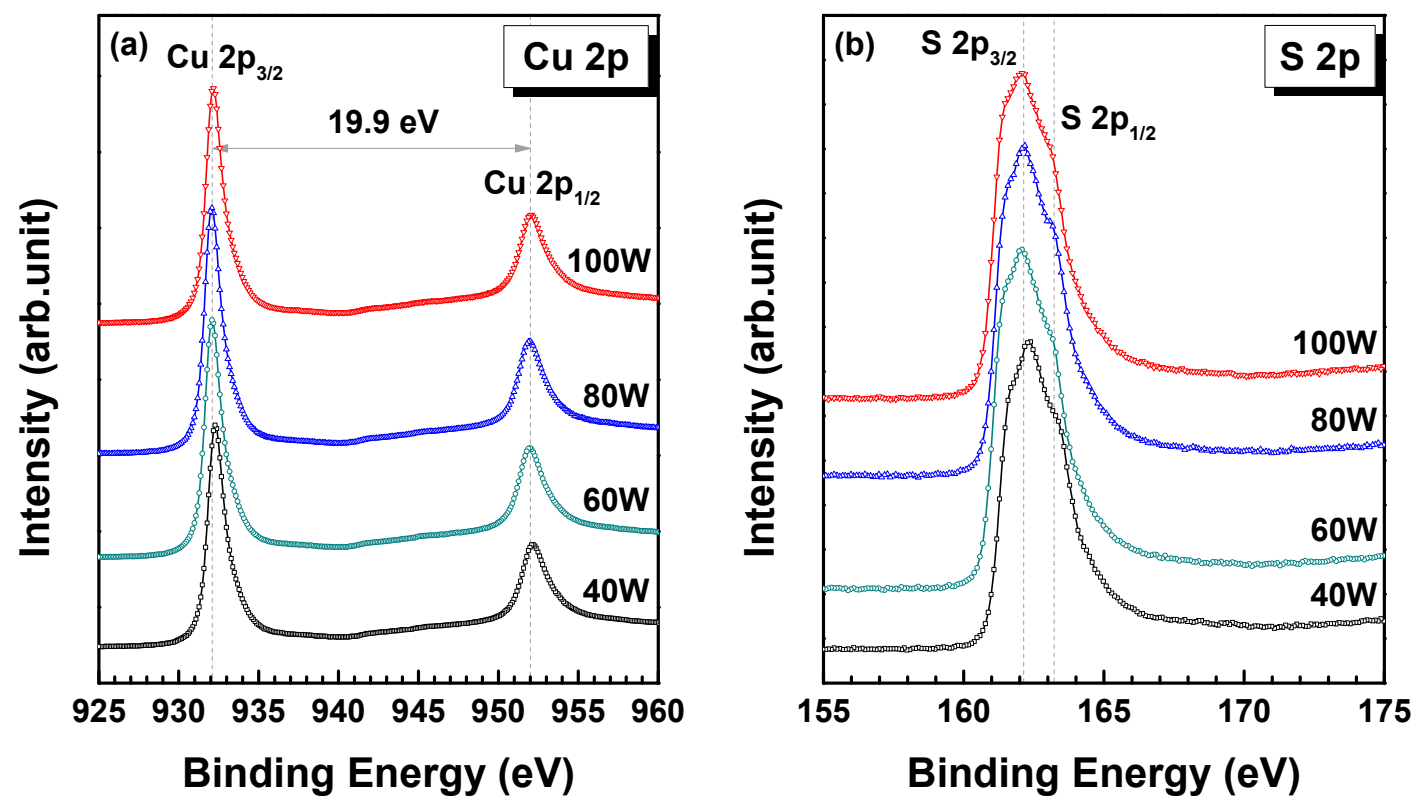

Figure 4. X-ray photoelectron spectroscopy (XPS) spectra of CuS thin films at different sputtering powers: (a) $\mathrm{Cu} 2 \mathrm{p}$ and (b) $\mathrm{S} 2 \mathrm{p}$ peaks.

\subsection{CuS Thin-Film Optical Properties}

Figure 5 shows the optical transmittance spectrum of the CuS thin film measured at wavelengths ranging from 400 to $1200 \mathrm{~nm}$. The transmittance spectrum for the CuS thin film deposited with $40 \mathrm{~W}$ RF power appeared above the 400 to $1200 \mathrm{~nm}$ range, and a clear peak form was observed with a transmittance of approximately less than $18 \%$ in the visible region of 450 to $800 \mathrm{~nm}$. For the $60 \mathrm{~W}$ condition, a peak of approximately less than $6 \%$ was observed in the range from 450 to $750 \mathrm{~nm}$, which was significantly lower than that of $40 \mathrm{~W}$. A transmittance of approximately less than $2 \%$ was observed in the range of $500-700 \mathrm{~nm}$ for the $80 \mathrm{~W}$, while a transmittance of less than $1 \%$ was observed in the range of 500-650 $\mathrm{nm}$ for the $100 \mathrm{~W}$. The maximal center point of the transmittance spectrum peaks moved from 560 (at $40 \mathrm{~W}$ ) to $570 \mathrm{~nm}$ (at $100 \mathrm{~W}$ ) as RF power increased. The cases of the CuS thin films deposited at RF powers, except for the $40 \mathrm{~W}$, were observed to be nontransmissive in the near-infrared (NIR) region $(\lambda>750 \mathrm{~nm})$. This transmittance reduction was determined to be a major cause of the increase in CuS thin-film thickness as RF power increased. Results in Figure 5, with a transmittance of $10 \%-20 \%$ in the visible (Vis.) region and nearly zero in the infrared (IR) region, were in good agreement with the optical properties of the CuS thin film reported by Nair's group [22]. The drop down of the transmission spectrum, starting at the $560 \mathrm{~nm}$ or $570 \mathrm{~nm}$ wavelength and extending into the NIR region, is consistent with the literature to demonstrate the typical metallic behavior of CuS [23]. The main reason for the great absorption of light in the NIR region is due to the nanocrystalline nature of the films (great amount of grain boundaries), and the high concentration of charge carriers (holes) derived from the crystalline structure [24]. The transmitted NIR light decreased with increasing thickness and reached almost zero for the thicker CuS films. In the visible region, a relatively high transmission followed by an absorption edges can be observed, indicating typical semiconductor behavior. In addition, the fall down of transmitted light could be due to the forbidden band gap of CuS [25]. 


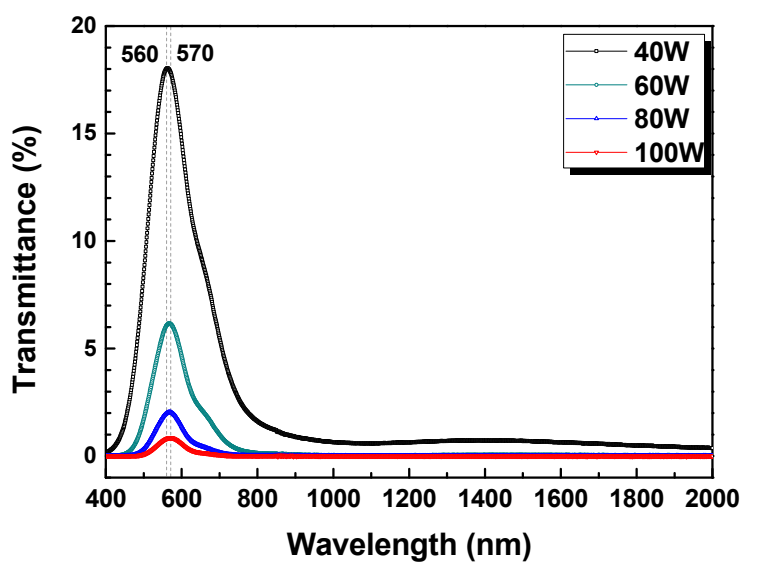

Figure 5. Optical transmittance spectra of CuS thin films grown at different sputtering powers.

The band-gap energy ( $\left.E_{g}\right)$ of the CuS thin film was calculated using the Tauc plot for absorption coefficient $\alpha$ obtained from the transmittance spectra, and the results are shown in Figure 6 [26]. The band-gap energy of the CuS thin film deposited with a sputtering power of $40 \mathrm{~W}$ was $2.68 \mathrm{eV}$. The band-gap energy with increasing power was $2.57 \mathrm{eV}$ for $60 \mathrm{~W}, 2.56 \mathrm{eV}$ for $80 \mathrm{~W}$, and $2.47 \mathrm{eV}$ for $100 \mathrm{~W}$, showing a decreasing trend. This tendency was determined to be a result of the improvement in crystallinity and increased thickness of the CuS thin film as deposition power increased, as observed through XRD patterns (Figure 1), Raman spectra (Figure 2), and FESEM images (Figure 3).

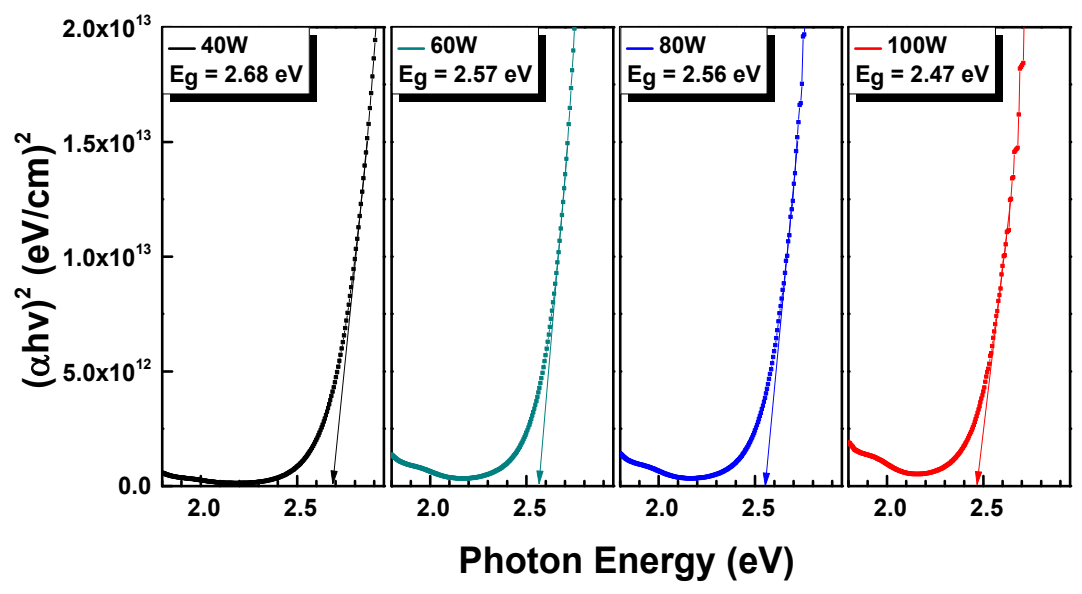

Figure 6. Plot $(\alpha \mathrm{h} v)^{2}$ versus photon energy (hv) of CuS thin films grown at different sputtering powers.

\subsection{Photovoltaic Performance of CuS/SnS Absorber-Based Solar Cells}

A number of studies have reported on the value and nature of the energy band gaps of covellite CuS thin films. The direct band gaps reported in the literature lie in the range from 2.05 to $2.58 \mathrm{eV}[3,12,16,20]$. The band gaps of CuS thin films prepared in this study also ranged from 2.47 to $2.68 \mathrm{eV}$. However, these band-gap ranges are not suitable for light-absorbing layers for solar cells. Therefore, a different approach is needed than directly applying the CuS thin film of this type to the absorber layer. $\mathrm{R}$. Chierchia's research group fabricated $\mathrm{Cu}_{2} \mathrm{SnS}_{3}$ (CTS) thin films by a two-step procedure in which a CuS thin film was deposited by DC sputtering; then, the SnS thin film was grown by RF magnetron sputtering. The CTS thin films were optimized for use as absorber in solar cells at two different sulfurization temperatures. The CTS thin film sulfurized at $520{ }^{\circ} \mathrm{C}$ revealed the energy band gap of $0.92 \mathrm{eV}$, and the CTS-based solar cell achieved power-conversion efficiency (PCE) of 3.05\% [27].

This approach is one of the more efficient methods of applying covellite CuS thin films as absorbing layers in solar cells. CuS/SnS-absorber layers of 1 um thickness were deposited by RF magnetron sputtering. CuS thin films with a thickness of $500 \mathrm{~nm}$ were grown on glass substrates at a room 
temperature with various sputtering powers of $40-100 \mathrm{~W}$. To prepare the CuS/SnS absorber layer, RF power and substrate temperature were adjusted to $60 \mathrm{~W}$ and $300{ }^{\circ} \mathrm{C}$ and a $500 \mathrm{~nm}$ thick SnS thin film was deposited on the CuS samples, respectively. Figure 7 shows the optical transmittance of $\mathrm{CuS} / \mathrm{SnS}$ absorber layers grown at a substrate temperature of $300^{\circ} \mathrm{C}$ in the $400-2000 \mathrm{~nm}$ spectral region. The transmission spectrum in Figure 7 is clearly distinguished from that in Figure 5. The absorption edge shifted to a wavelength near $800 \mathrm{~nm}$, and the spectra range was also extended to the $2000 \mathrm{~nm}$ wavelength, including the NIR region. Transmittance in the NIR region $(\lambda=780-2000 \mathrm{~nm})$ for the CuS/SnS thin films decreased from $50 \%$ to $48 \%$ on average as the deposition power of the CuS thin film increased from 40 to $100 \mathrm{~W}$.

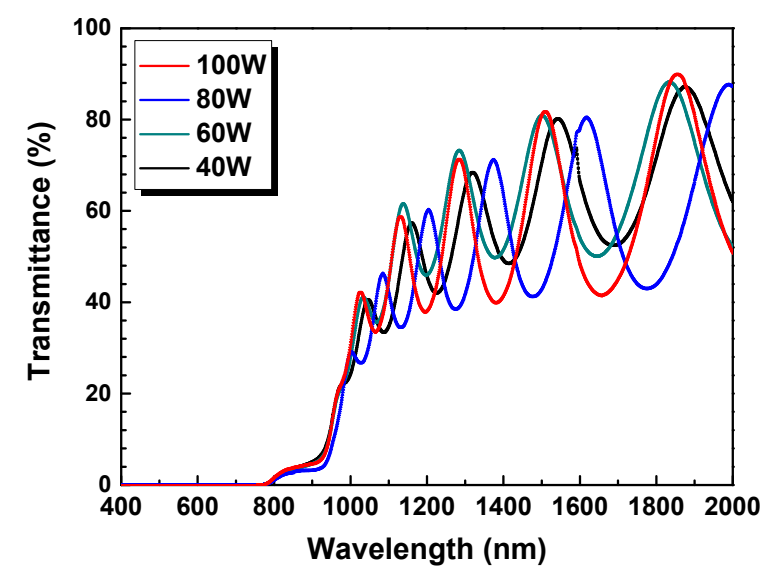

Figure 7. Optical transmittance spectra of $\mathrm{CuS} /$ tin sulfide $(\mathrm{SnS})$ absorber layers grown at a substrate temperature of $300{ }^{\circ} \mathrm{C}$ as function of various sputtering powers for $\mathrm{CuS}$ thin films.

The band gap for the CuS/SnS absorber layers is shown in Figure 8. As the sputtering power for depositing the CuS thin film was increased from $40 \mathrm{~W}$ to $100 \mathrm{~W}$, the band gap of the CuS/SnS thin films was changed from $1.58 \mathrm{eV}$ to $1.57 \mathrm{eV}$, showing a slight difference of $0.01 \mathrm{eV}$. The results show that when the covellite CuS film was stacked together with the SnS film, and given appropriate process conditions, the CuS film could be sufficiently applied as an absorbing layer of the solar cell. In order to apply a CuS thin film in solar cells, photovoltaic cells with a glass/Mo/absorber (CuS/SnS)/CdS/i-ZnO/ITO/Al structure were fabricated, as shown in Figure 9. The effect of sputtering powers for the deposition of $\mathrm{CuS}$ thin films on the performance of CuS/SnS absorber-based solar cells was investigated.

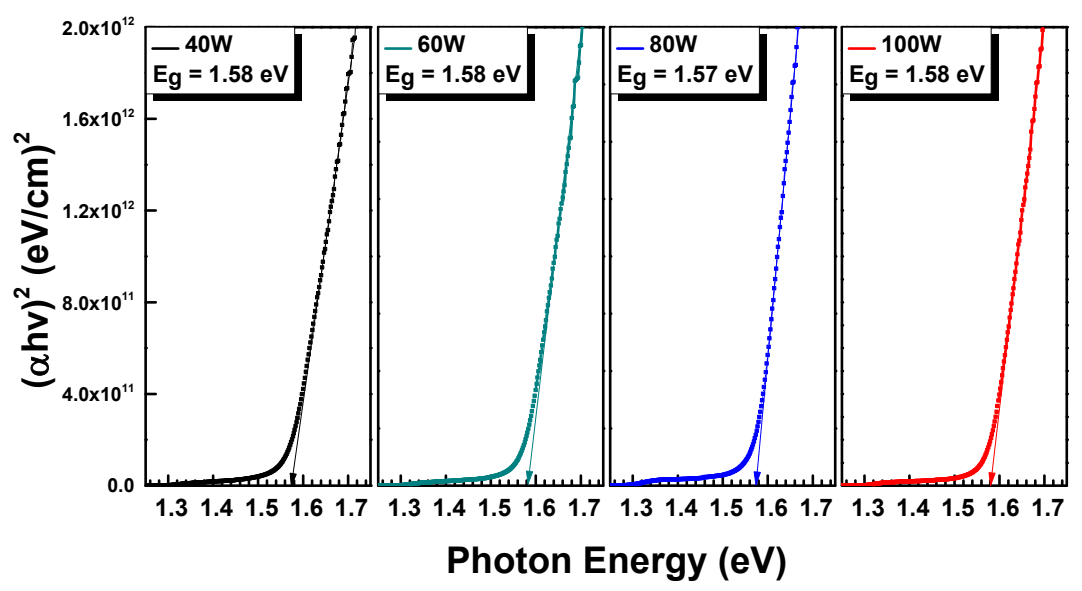

Figure 8. Plot $(\alpha h v)^{2}$ versus photon energy (hv) of CuS/SnS absorber layers grown at a substrate temperature of $300{ }^{\circ} \mathrm{C}$ as function of various sputtering powers for $\mathrm{CuS}$ thin films. 


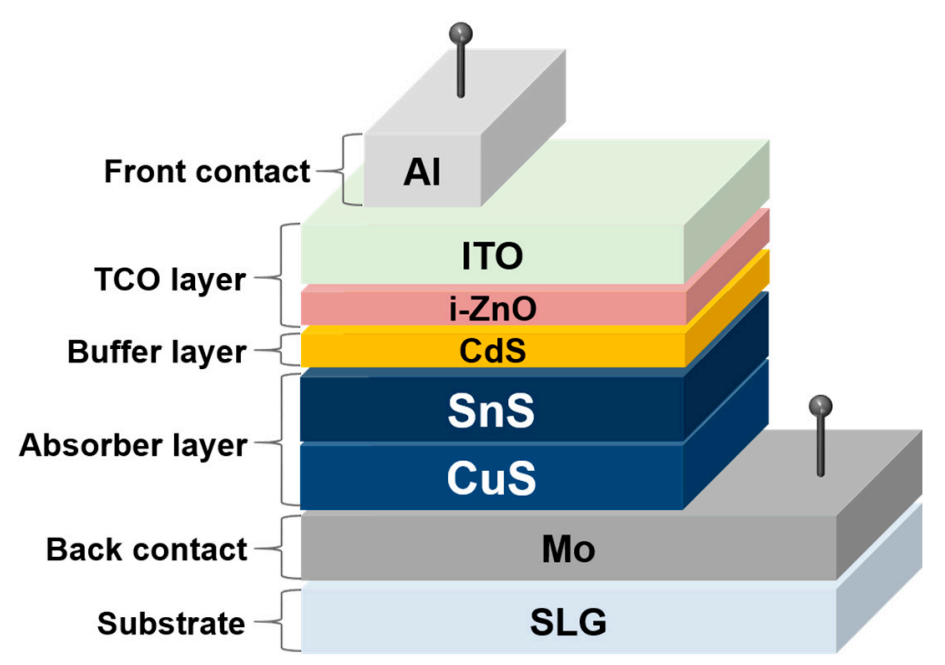

Figure 9. CuS/SnS absorber-based solar cell.

Figure 10 shows the current density-voltage $(\mathrm{J}-\mathrm{V})$ characteristics of the fabricated thin-film solar-cell device based on the CuS/SnS absorber layer. In order to investigate how the deposition power's effect on CuS thin-film growth affected CuS/SnS absorber-based solar-cell performance, the J-V characteristics of all samples were measured, and results are shown in Table 2. The efficiency of the solar cell manufactured with a CuS thin film deposited at the power condition of $40 \mathrm{~W}$ was $0.19 \%$, while efficiency was $0.25 \%$ and $0.38 \%$ for 60 and $80 \mathrm{~W}$, respectively. The $100 \mathrm{~W}$ power condition showed the highest efficiency of $0.39 \%$. As shown in Figure 10 , open-circuit voltage $\left(\mathrm{V}_{\mathrm{oc}}\right)$, short-circuit current density $\left(\mathrm{J}_{\mathrm{sc}}\right)$, and fill factor $(\mathrm{FF})$ were measured to be $115 \mathrm{mV}, 9.81 \mathrm{~mA} / \mathrm{cm}^{2}$, and $35 \%$, respectively. The reason for this increased efficiency can be attributed to the structural and optical property improvements of the CuS thin film as power increased, as discussed earlier.

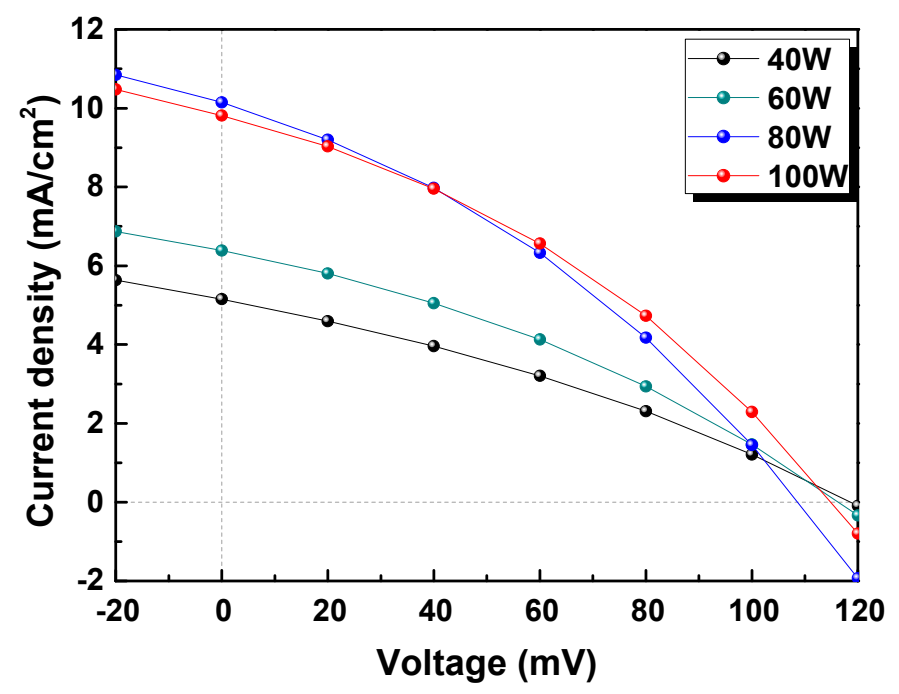

Figure 10. Current density-voltage (J-V) characteristics of CuS/SnS absorber-based solar cells under AM 1.5 illumination. 
Table 2. Current density-voltage (J-V) characteristics of CuS/SnS absorber-based solar cells evaluated from solar simulator as function of $\mathrm{CuS}$ sputtering powers $\left(\mathrm{P}_{\mathrm{S}}\right)$. PCE-power conversion efficiency.

\begin{tabular}{ccccc}
\hline $\mathbf{P}_{\mathbf{s}}(\mathbf{W})$ & $\mathbf{V}_{\mathbf{o c}}(\mathbf{m A})$ & $\mathbf{J}_{\mathbf{s c}}\left(\mathbf{m A} \mathbf{/ \mathbf { c m } ^ { 2 }}\right)$ & $\mathbf{F F} \mathbf{( \% )}$ & PCE (\%) \\
\hline 40 & 119 & 5.15 & 31 & 0.19 \\
60 & 116 & 6.39 & 33 & 0.25 \\
80 & 109 & 10.15 & 34 & 0.38 \\
100 & 115 & 9.81 & 35 & 0.39 \\
\hline
\end{tabular}

\section{Conclusions}

Covellite CuS thin films were fabricated using RF magnetron sputtering with different sputtering powers. The effects of sputtering powers on the structural, compositional, morphological, and optical properties of $\mathrm{CuS}$ thin films were investigated in detail. The CuS thin films deposited at varying RF powers showed preferred growth on the (110) plane corresponding to the diffraction angle of $2 \theta \approx 48.1^{\circ}$, and diffraction peak intensity for the (110) plane showed an increasing tendency proportional to power. The peaks for the two bands shown in the Raman spectrum $\left(265\right.$ and $\left.474 \mathrm{~cm}^{-1}\right)$ accurately matched the typical Raman spectrum values for covellite CuS. FESEM image analysis revealed that CuS crystal growth was in a direction vertical to the substrate, and there was a maximal thickness increase of approximately $330 \mathrm{~nm}$, along with gradual increases in grain size and grain-boundary spacing. In the XPS study, two strong peaks for the $\mathrm{Cu} 2 \mathrm{p}_{3 / 2}$ and $\mathrm{Cu} 2 \mathrm{p}_{1 / 2}$ binding energies corresponding to the $\mathrm{Cu}^{2+}$ state were observed at 932.1 and $952 \mathrm{eV}$, respectively. Peaks for the $\mathrm{S} 2 \mathrm{p}_{3 / 2}$ and $\mathrm{S} 2 \mathrm{p}_{1 / 2}$ binding energies corresponding to the $\mathrm{S}^{2-}$ state were observed at 162.2 and $163.2 \mathrm{eV}$, respectively. The results above confirmed that CuS thin films were successfully fabricated with a pure covellite CuS phase, with no existing impurity phase. Transmittance of the CuS thin film deposited at the RF power of $40 \mathrm{~W}$ was approximately $18 \%$ in the wavelength range from 450 to $850 \mathrm{~nm}$, while transmittance of the CuS thin film deposited at $100 \mathrm{~W}$ was less than $1 \%$ in the wavelength range from 500 to $650 \mathrm{~nm}$. CuS thin-film transmittance and transmission range decreased as RF power increased. As the absorption edge moved towards the long wavelength range, the band-gap energy decreased from 2.68 (at $40 \mathrm{~W}$ ) to $2.47 \mathrm{eV}$ (at $100 \mathrm{~W})$.

We investigated the properties of a thin-film solar cell, fabricated by stacking the SnS thin film on a CuS thin film of equal thickness to compose the buffer layer, window layer, and electrode on top of the CuS/SnS-absorber. The results showed that the open-circuit voltage $\left(\mathrm{V}_{\mathrm{oc}}\right)$, short-circuit current density $\left(\mathrm{J}_{\mathrm{sc}}\right)$, and fill factor $(\mathrm{FF})$ were $115 \mathrm{mV}, 9.81 \mathrm{~mA} / \mathrm{cm}^{2}$, and $35 \%$, respectively. The highest conversion efficiency of $0.39 \%$ was exhibited by the solar-cell sample incorporating a CuS thin film deposited at the RF power of $100 \mathrm{~W}$.

Author Contributions: Conceptualization, D.S. and D.H.; methodology, D.H., J.H.P., and C.S.S.; software, D.S. and S.L.; validation, D.H., J.H.P., and Y.G.S.; formal analysis, S.L. and W.-J.C.; investigation, D.S., D.R.K., and S.L.; resources, C.S.S., Y.K., and Y.G.S.; data curation, W.-J.C. and D.R.K.; writing-original-draft preparation, D.S. and D.H.; writing-review and editing, Y.G.S. and D.H.; visualization, D.R.K. and S.L.; supervision, D.H., C.S.S., and Y.G.S. All authors have read and agreed to the published version of the manuscript.

Funding: This work was supported by the Korea Institute of Energy Technology Evaluation and Planning (KETEP) and the Ministry of Trade, Industry \& Energy (MOTIE) of the Republic of Korea (No. 20173010013140); and by the National Research Foundation of Korea (NRF) grant funded by the Korea government (MSIT) (No. 2017R1C1B5018403); and by the National Research Foundation (NRF-2018R1A5A1025594) of the Ministry of Science and ICT.

Conflicts of Interest: The authors declare no conflict of interest.

\section{References}

1. Chaki, S.H.; Tailor, J.P.; Deshpande, M.P. Covllite CuS-Single crystal growth by chemical vapour transport (CVT) technique and characterization. Mat. Sci. Semicon. Proc. 2014, 27, 577-585. [CrossRef] 
2. Hu, R.; Zhang, R.; Ma, Y.; Liu, W.; Chu, L.; Mao, W.; Zhang, J.; Yang, J.; Pu, Y.; Li, X. Enhanced hole transfer in hole-conductor-free perovskite solar cells via incorporating $\mathrm{CuS}$ into carbon electrodes. Appl. Phys. Lett. 2018, 462, 840-846. [CrossRef]

3. Ivan, G. Optical and electrical properties of copper sulfide films of variable composition. J. Solid State Chem. 1995, 114, 469-475.

4. Page, M.; Niitsoo, O.; Itzhaik, Y.; Cahen, D.; Hodes, G. Copper sulfide as a light absorber in wet-chemical synthesized extremely thin absorber (ETA) solar cells. Energy Environ. Sci. 2009, 2, 220-223. [CrossRef]

5. Chung, J.S.; Sohn, H.J. Electrochemical behaviors of $\mathrm{CuS}$ as a cathode material for lithium secondary batteries. J. Power Sources 2002, 108, 226-231. [CrossRef]

6. Sabah, F.A.; Ahmed, N.M.; Hassan, Z.; Rasheed, H.S. High performance CuS p-type thin film as a hydrogen gas sensor. Sens. Actuators A 2016, 249, 68-76. [CrossRef]

7. Masar, M.; Urbanek, M.; Urbanek, P.; Machovska, Z.; Maslik, J. Synthesis, characterization and examination of photocatalytic performance of hexagonal covellite CuS nanoplates. Mater. Chem. Phys. 2019, 237, 121823. [CrossRef]

8. Isac, L.; Andronic, L.; Enesca, A.; Duta, A. Copper sulfide films obtained by spray pyrolysis for dyes photodegradation under visible light irradiation. J. Photochem. Photobiol. A Chem. 2013, 252, 53-59. [CrossRef]

9. Lu, Q.; Gao, F.; Zhao, D. One-step synthesis and assembly of copper sulfide nanoparticles to nanowires, nanotubes, and nanovesicles by a simple organic amineassisted hydrothermal process. Nano Lett. 2002, 2, 725-728. [CrossRef]

10. Reijnen, L.; Meester, B.; Lange, F.D.; Joop Schoonman, A.; Goossens, A. Comparison of CuxS films grown by atomic layer deposition and chemical vapor deposition. Chem. Mater. 2005, 17, 2724-2728. [CrossRef]

11. Tripathi, T.S.; Lahtinen, J.; Karppinen, M. Atomic layer deposition of conducting CuS thin films from elemental sulfur. Adv. Mater. Interfaces 2018, 5, 1701366. [CrossRef]

12. Ghribi, F.; Alyamani, A.; Ben Ayadi, Z.; Djessas, K.; EL Mir, L. Study of CuS thin films for solar cell applications sputtered from nanoparticles synthesised by hydrothermal route. Energy Procedia 2015, 84, 197-203. [CrossRef]

13. Dong, Y.; He, J.; Sun, L.; Chen, Y.; Yang, P.; Chu, J. Effect of sulfurization temperature on properties of $\mathrm{Cu} 2 \mathrm{SnS} 3$ thin films and solar cells prepared by sulfurization of stacked metallic precursors. Mater. Sci. Semicond. Process. 2015, 38, 171-176. [CrossRef]

14. Hong, X.; Xu, Z.; Zhang, F.; He, C.; Gao, X.; Liu, Q.; Guo, W.; Liu, X.; Ye, M. Sputtered seed-assisted growth of CuS nanosheet arrays as effective counter electrodes for quantum dot-sensitized solar cells. Mater. Lett. 2017, 203, 73-76. [CrossRef]

15. Patterson, A.L. The scherrer formula for X-ray particle size determination. Phys. Rev. 1939, 56, 978-982. [CrossRef]

16. Adhikaru, S.; Sarkar, D.; Madras, G. Hierarchical design of CuS architectures for visible light photocatalysis of 4-chlorophenol. ACS Omega 2017, 2, 4009-4021. [CrossRef]

17. Minceva-Sukarova, B.; Najdoski, M.; Grozdanov, I.; Chunnilall, C.J. Raman spectra of thin solid films of some metal sulfides. J. Mol. Struct. 1997, 410-411, 267-270. [CrossRef]

18. Murali, B.; Parui, J.; Chandan, K.G.; Mayoori, A.; Krupanidhi, S.B. Synthesis of CuS nanoplates and self-assembled hierarchical architectures by solvothermal method. Adv. Sci. Eng. Med. 2013, 5, 105-111. [CrossRef]

19. Yeryukov, N.A.; Milekhin, A.G.; Sveshnikova, L.L.; Duda, T.A.; Pokrovsky, L.D.; Gutakovskii, A.K.; Batsanov, S.A.; Rodyakina, E.E.; Latyshev, A.V.; Zahn, D.R.T. Synthesis and characterization of CuxS ( $x=1-2)$ nanocrystals formed by the Langmuir-blodgett technique. J. Phys. Chem. C 2014, 118, 23409-23414. [CrossRef]

20. Pejjai, B.; Reddivari, M.; Kotte, T.R.R. Phase controllable synthesis of CuS nanoparticles by chemical co-precipitation method: Effect of copper precursors on the properties of CuS. Mater. Chem. Phys. 2020, 239, 122030. [CrossRef]

21. Zhang, L.J.; Xie, T.F.; Wang, D.J.; Li, S.; Wang, L.L.; Chen, L.P.; Lu, Y.C. Noble-metal-free CuS/CdS composites for photocatalytic $\mathrm{H} 2$ evolution and its photogenerated charge transfer properties. Int. J. Hydrogen Energy 2013, 38, 11811-11817. [CrossRef]

22. Nair, P.K.; Garcia, V.M.; Fernandez, A.M.; Ruiz, H.S.; Nair, M.T.S. Otimization of chemically deposited CuxS solar control coatings. J. Phys. D 1991, 24, 441-449. [CrossRef] 
23. Conejeros, S.; Moreira, I.D.P.R.; Alemany, P.; Canadell, E. Nature of holes, oxidation states, and hypervalency in covellite (CuS). Inorg. Chem. 2014, 53, 12402-12406. [CrossRef] [PubMed]

24. Morales-García, A.; Soares, A.L.; Dos Santos, E.C.; Abreu, H.A.D.; Duarte, H.A. First-principles calculations and electron density topological analysis of covellite (CuS). J. Phys. Chem. A 2014, 118, 5823-5831. [CrossRef] [PubMed]

25. Ramírez-Esquivel, O.Y.; Mazón-Montijo, D.A.; Montiel-González, Z.; Aguirre-Tostado, F.S. Deposition of highly crystalline covellite copper sulphide thin films by SILAR. Phys. Status Solidi A 2017, 214, 1700500. [CrossRef]

26. Tauc, J.; Grigorovici, R.; Vancu, A. Optical properties and electronic structure of amorphous germanium. Phys. Stat. Sol. 1966, 15, 627-637. [CrossRef]

27. Chierchia, R.; Pigna, F.; Valentini, M.; Malerba, C.; Salza, E.; Mangiapane, P.; Polichetti, T.; Mittiga, A. Cu2SnS3 based solar cell with 3\% efficiency. Phys. Status Solidi C 2016, 13, 35-39. [CrossRef]

(C) 2020 by the authors. Licensee MDPI, Basel, Switzerland. This article is an open access article distributed under the terms and conditions of the Creative Commons Attribution (CC BY) license (http://creativecommons.org/licenses/by/4.0/). 